\title{
Assessing Progress towards SDG2: Trends and Patterns of Multiple Malnutrition in Young Children under 5 in West and Central Africa
}

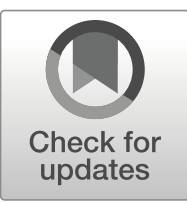

\author{
Marco Pomati ${ }^{1}$ (D) Shailen Nandy ${ }^{1}$
}

Accepted: 9 August 2019/Published online: 4 September 2019

(C) The Author(s) 2019

\begin{abstract}
The co-occurrence of different forms of malnutrition in young children is known to carry differential risks of morbity and mortality. Despite this, there are few, if any, systematic analyses of the prevalence of multiple anthropometric failures (or deficits) in young children under 5 . This paper presents the results of the first such an analysis done on data from one of the poorest geographic regions of the world - West and Central Africa. Using data from the demographic and health surveys (DHS) and UNICEF's Multiple Indicator Cluster Surveys (MICS), the paper details the prevalence and patterning of child malnutrition using a combination of conventional measures and the Composite Index of Anthropometric Failure (CIAF) for the period 1990-2015. It shows the advantages of the CIAF indicator for gauging the full extent of malnutrition and the ability of an indicator of 'Multiple Malnutrition' to identify children under 5 with higher risk of mortality. It also shows how relatively little progress has been made in reducing the extent of malnutrition and emphasises the importance of tracking progress by looking at both rates and total number of affected children. Malnutrition across the region remains strongly associated with household wealth and education. Poorer, rural households are much more likely to experience malnutition, but the widespread prevalence of poor living conditions in urban areas has the potential to undermine any gains made in reducing malnutrition.
\end{abstract}

Keywords Malnutrition · Poverty · Living standards · Africa $\cdot$ Sustainable development goals · DHS · CIAF

Marco Pomati

PomatiM@Cf.ac.uk

Shailen Nandy

NandyS1@Cf.ac.uk

1 School of Social Sciences, Cardiff University, Glamorgan Building, King Edward VII Avenue,

Cardiff, Wales CF24 3PG, UK 


\section{Introduction}

Malnutrition continues to be a major determinant of child health and survival in low and middle-income countries (LMICs). International efforts like the United Nations Sustainable Development Goals (SDGs) rightly focus attention and resources on this important issue, and public health and epidemiological research seek to explain its causes and consequences, using the conventional indicators of growth: Wasting, Stunting and Underweight (Cesare et al. 2015; Nabwera et al. 2017). Other studies have shown how different forms of malnutrition, or combinations of anthropometric failure or deficits, entail differential risks for child health and survival rates (Olofin et al. 2013), with children who experience multiple anthropometric deficits more likely to have higher morbidity rates. These children have also been shown to be at greater risk of early death. Studies demonstrate an up to twelve-times greater risk of early mortality for children with multiple anthropometric deficits (McDonald et al. 2013).

Between 1990 and 2014, many sub-Saharan African countries saw increases in undernutrtion among young children; across the continent there was a $23 \%$ rise in the number of children under five experiencing Stunting (i.e. low height for age, a measure of chronic food deprivation) with around 58 million children affected (UNICEF, WHO, and World Bank, 2015). Many of these children also experienced Wasting (i.e. low weight for height, and a measure of more immediate food deprivation or illness), and the co-occurrence of these anthropometric deficits, undoubtedly presented families and health systems with challenges of raised morbidity and mortality (McDonald et al. 2013). Despite the known links between nutrition, morbidity and mortality, however, it remains the case that there are few reliable data on the prevlance of 'multiple malnutrition' in children in sub-Saharan Africa.

This paper provides the first estimates of the prevalence of aggregate and multiple malnutrition in one of the poorest regions of the world. Using household survey microdata collected on children under five, from nationally-representative Demographic and Health Surveys (DHS) and UNICEF's Multiple Indicator Cluster Surveys (MICS) (Corsi et al. 2012; Hancioglu \& Arnold. 2013; Vaessen 1996) we present (i) national and regional estimates of the extent, and trends, of children experiencing one or more anthropometric failures, and (ii) data on the experience of multiple forms of malnutrition at the same time. We also (iii) estimate the number of children 'missed' by conventional indicators of malnutrition, and argue that the scale of the challenge facing communities, governments and international actors is greater than currently realised.

Countries and UN agencies require reliable, high quality data if the world is to succesfully meet the Sustainable Development Goals (SDGs), and particular SDG 2.2, which is, by 2030, to "end all forms of malnutrition, including achieving, by 2025, the internationally agreed targets on stunting and wasting in children under 5 years of age, and address the nutritional needs of adolescent girls, pregnant and lactating women and older persons". This paper shows how the measures of stunting and wasting, used on their own, miss significant numbers of young children who experience malnutrition, but that this can be avoided by using an aggregate measure known as the Composite Index of Anthropometric Failure (CIAF). We show how the CIAF can be disaggregated, to identify children experiencing a combination of failures (multiple malnutrition), who are likely to be at greater risk of morbidity and premature mortality. We also 
show that education and poverty remain the key drivers of malnutrition, in both rural and urban areas, and that progress in west and central Africa has been slow in the 2000 s, with reductions in the percentage of children malnourished lagging behind the rates of population growth.

\section{Background}

The most common indicators of malnutrition in young children use anthropometric data (i.e. heights and weights) and are:

- Stunting, an indicator of chronic or long-term food and nutrition deprivation, where children fail to reach the expected height (or length) for their age;

- Wasting, an indicator of more recent/immediate food/nutrition deprivation and/or ill health, resulting in weight loss or insufficient weight gain, leading to a lower than expected weight for height (or length); and

- Underweight, reflecting when children fail to reach an expected weight for their age, either because of wasting or stunting or both.

Assessments of the nutritional profile of a country's children depend on the indicator used. According to the World Health Organization (WHO), cut-off values for public health significance differ for each indicator, as shown in the table below. While a prevalence of $20 \%$ for underweight may suggest a high level of malnutrition, a similar figure for stunting would appear to merit less concern. A $20 \%$ rate for wasting would reflect a critical level of malnutrition, requiring rapid mobilisation and nutrition interventions, in order to prevent premature mortality (UNICEF 2015) (Table 1).

Underweight was used to assess progress to target 1.C of the Millennium Development Goals (MDGs), "to halve between 1990 and 2015 the proportion of people who suffer from hunger". This target was missed at the world level (United Nations, 2015); in sub-Saharan Africa the proportion of children experiencing moderate of severe underweight fell from $29 \%$ to $20 \%$, a fall of around $30 \%$ - less than the $50 \%$ target. The UN MDG Report 2015 also noted that "due to the region's growing

Table 1 Prevalence cut-off values for public health significance

\begin{tabular}{ll}
\hline Underweight & $<10 \%$ : low prevalence \\
& $10-19 \%$ : Medium prevalence \\
& $20-29 \%$ : High prevalence \\
& $\geq 30 \%$ : Very high prevalence \\
& $<20 \%$ : low prevalence \\
& $20-29 \%$ : Medium prevalence \\
Stunting & $30-39 \%$ : High prevalence \\
& $\geq 40 \%:$ Very high prevalence \\
& $<5 \%:$ Acceptable \\
& $5-9 \%:$ Poor \\
& $10-14 \%$ : Serious \\
& $15 \%:$ Critical \\
\end{tabular}


population, the number of underweight children has actually risen"; a combination of slow progress, persistent poverty, and high population growth meant that in 2015 there were more malnourished children in the region than when the goals were set, in 2000.

The MDGs were replaced by the SDGs, with a new, broader target to end hunger, achieve food security and improved nutrition and promote sustainable agriculture (UNDESA, 2016). This time different indicators were chosen to reflect hunger and malnutrition; these included the proportions of children experiencing stunting, wasting and (perhaps to reflect conditions at the other end of the malnutrition spectrum) overweight (i.e. a high body mass index). In 2016 around one-third (34\%, around 57 million) of African children under 5 experienced stunting (UNDESA 2017). Overweight generally affects much smaller numbers of children, typically less than $10 \%$; around $4 \%$ of children in Africa were overweight in 2016, a figure unchanged since 2000. There are sub-national differences in the patterning of overweight, which will present different challenges for public health and nutrition. Within the African context, given the relatively low percentage of overweight children, the focus has therefore shifted away from underweight and towards the monitoring of stunting and wasting separately. Although children who are experiencing either stunting, wasting or underweight have greater mortality rates, the focus on stunting and wasting (and not underweight) may indeed provide policy makers with two theoretically distinct indicators: one of chronic and the other of more recent food and nutrition deprivation. Nevertheless, in this paper we argue that there is a clear rationale for considering the total number of children experiencing any form of malnutrition as well as those experiencing multiple forms of malnutrition simultaneously. We also argue that to do so we should also consider children who are underweight instead of focusing only on stunting and wasting.

At an individual level, and particularly among young children, aggregate (CIAF) and multiple (MM) malnutrition may reflect either the experience of stunting, wasting and/or underweight, or any combination of these anthropometric failures (Svedberg 2000; UNICEF, WHO, and World Bank, 2015). The Emergency Nutrition Network highlighted an important policy implication of MM, noting that despite the fact that children frequently experience wasting and stunting concurrently, “...in the humanitarian and development architecture...wasting programmes (are) still largely funded and implemented under the 'humanitarian' remit, while stunting resides under 'development" (Khara \& Dolan 2014: 5). This is because wasting is viewed as an acute condition, and stunting as a longer term development problem. What is needed is for policy, programming and resources to be brought together to tackle multiple malnutrition simultaneously, as "divergences between programs focused on acute malnutrition and those focused on chronic malnutrition constitute important impediments to the effective delivery of comprehensive services." (Bergeron \& Castleman 2012: 247). The provision of evidence about aggregate and multiple malnutrition is therefore an important contribution (Myatt et al. 2018) and this paper aims to articulate the rationale for such measures as well as how to construct these measures.

\subsection{Measuring Malnutrition}

While stunting and wasting reflect distinct biological processes, used on their own they do not provide a picture of the aggregate extent of malnutrition (Svedberg 2000). Some 
children who are stunted might not be underweight or experience wasting, and some children who experience wasting may not be underweight. Used singly, these indicators inevitably underestimate the extent of malnutrition in young children in a population (Nandy \& Svedberg, 2012). In 2000, Svedberg proposed the use of a Composite Index of Anthropometric Failure (CIAF) which showed if a child experienced, either singly or in combination, stunting, wasting or underweight (Svedberg 2000). The CIAF was first operationalised and used to confirm that malnutrition in India was being significantly underestimated, with millions of children 'missed' from national estimates (Nandy et al. 2005). The implications of this for planning and resourcing are self-evident (Nandy \& Miranda, 2008).

The CIAF shows the aggregate prevalence of child malnutrition in a population, and in a disaggregated form, how malnutrition is patterned - i.e. how many children experience a single anthropometric failure (e.g. only wasting, or only stunting), a double failure (i.e. wasting and underweight), or even a triple failure - simultaneous wasting, stunting and underweight. This information is important since different forms of malnutrition are associated with different morbidity and mortality risks (Olofin et al. 2013; Pelletier et al. 1995; Schroeder \& Brown 1994; Tomkins, 2000; Tomkins \& Watson 1989; Vella et al. 1994). Analysis of pooled cohort studies from countries in Africa, Asia and Latin America (McDonald et al. 2013) quantified the mortality risk associated with different combinations of 'anthropometric deficits'; it shows that children experiencing either wasting, underweight or stunting have higher mortality rates than those who experience no anthropometric failures, and that multiple anthropometric failures have an ever greater risk of up to 12 times those of children with no deficits. Such analyses have led to a growing interest in use of the CIAF by researchers (Vollmer et al. 2017), and in particular organisations like UNICEF, interested in ensuring that the nutritional and developmental needs of children are reflected accurately and addressed. In fact, following calls by UNICEF and the WHO, the international Sustainable Development Goals (SDGs) have selected both Stunting and Wasting as indicators to reflect progress towards SDG target 2.2. Despite this, however, there are few estimates of aggregate (CIAF) and multiple malnutrition (MM) or of the co-occurrence of anthropometric failures (Multiple Malnutrition); this paper presents estimates for the CIAF and MM for countries in West and Central Africa.

\subsection{Education, Poverty and Rurality}

A child's nutritional status is determined by a range of inter-connected factors, acting at individual, household, local community, national and international levels (Khara \& Dolan 2014). Thus a child sick with dysentery, caused by poor living conditions (e.g. a dirt floor, no access to sanitation) in an urban slum community, in the capital city of a low income country whose government either lacks or is unable to implement effective anti-poverty policies, to ensure people have clean water, access to health care or adequate food security, in an international climate of increasing food prices, is exposed to factors at every level which affect her nutritional status.

Researchers use household asset-based 'wealth' indices as proxies for household socio-economic status (Booysen et al. 2008; Howe et al. 2008; S. O. Rutstein \& Johnson 2004), to stratify populations, and provide an indication of relative wealth and poverty. Others use the educational attainment of household members as it reflects 
knowledge-related capital of a household (Galobardes et al. 2007). In addition to these, in this paper we also look at the association between slum and non-slum conditions and child malnutrition. The UN-Habitat definition of slum-like conditions is based on five broad indicators:

(1) Durable housing of a permanent nature which protects against extreme climate conditions;

(2) Sufficient living space, of not more than three people per room;

(3) Access to safe water in sufficient amounts at an affordable price;

(4) Access to adequate sanitation in the form of a private or public toilet, shared if necessary, by a 'reasonable' number of people; and

(5) Security of tenure which prevents forced eviction.

Access to sanitation, safe water and durable housing are of particular relevance to a study of malnutrition, given that a lack of access increases the risk of diarrhoea and enteric infections, which are associated with anthropometric failure (Checkley et al. 2004; Checkley et al. 1997; Dillingham \& Guerrant 2004). In this paper we use the term "slum-like conditions" to conform to the UN-Habitat definition, although other terms such as "informal settlements" or "unsafe settlements" may also be used to describe this type of housing conditions.

\section{Data and Methods}

Estimates of child malnutrition are based on data collected in nationallyrepresentative household surveys. Two of the most widely used sources are the Demographic and Health Surveys (DHS) (Corsi et al. 2012; Vaessen 1996) and UNICEF's Multiple Indicator Cluster Surveys (Hancioglu \& Arnold. 2013; Pemberton et al. 2005), with both contributing to the World Health Organization's Nutrition Databases. This paper uses DHS data harmonised by the IPUMS DHS project (Heger Boyle et al. 2018) and also data from available MICS for countries lacking a DHS.

There have been seven phases of DHS since 1984: phase 1 (1984-1989), phase 2 (1988-1993), phase 3 (1992-1997), phase 4 (1997-2003), phase 5 (2003-2008), phase 6 (2008-2013) and phase 7 (2013-2018). Over 300 surveys have been conducted in over 90 countries using standardised questionnaires and methodologies, and multistage random cluster sampling (Aliaga \& Ren 2006; S.O. Rutstein \& Rojas 2003; Ties Boerma 1996). Each survey has between 150 and 300 clusters, with an average of 200 clusters. Cluster sizes are around 2-3 km, and are smaller in urban areas (Gerland 1996; Gordon 2002). Data are collected at community, household, and individual level, and are representative both nationally and sub-nationally.

The DHS provided the model for UNICEF's MICS, which were developed in the 1990s, in response to a need for data to track progress toward the goals set at the 1990 World Summit for Children. Five rounds of MICS have been conducted: MICS-I in 1995 in 65 countries, MICS-II in 2000 in 67 countries, MICS-III in 2005-06 in 56 countries, MICS-IV in 50 countries between 2009 and 2010, and MICS-V in 43 countries between 2012 and 2016. MICS-VI is currently (2017-2020). Like the 
DHS, MICS use multi-stage stratified random cluster samples and are representative nationally and sub-nationally.

The countries, sample sizes and surveys used in the analysis presented here are shown in Table 2.

Data were available for 18 of the 24 countries in the west and central Africa region, covering over $95 \%$ of children under- 5 in the region. Data for countries with surveys \pm 2 years from 2010 were used to make a regional estimate of the extent of multiple malnutrition for 2010. To estimate change over time, only countries with multiple rounds of data were used (these were Benin, Ghana, Mali, Nigeria, Sierra Leone, Burkina Faso and Senegal). As a result, the number of countries in the trend analysis

Table 2 Details of surveys used in the analysis of malnutrition

\begin{tabular}{|c|c|c|c|c|c|c|}
\hline Country & Year & Source & $\begin{array}{l}\text { Unweighted } \\
\text { Sample size }\end{array}$ & $\%$ Urban & $\%$ Rural & $\begin{array}{l}\text { Under } 5 \\
\text { Population }\end{array}$ \\
\hline Benin & 2001 & DHS & 3866 & 31 & 69 & $1,278,839$ \\
\hline Benin & 2006 & DHS & 12,246 & 37 & 63 & $1,455,957$ \\
\hline Benin* & 2011 & DHS & 7636 & 37 & 63 & $1,603,789$ \\
\hline Burkina Faso & 2003 & DHS & 8101 & 17 & 83 & $2,363,113$ \\
\hline Burkina Faso* & 2010 & DHS & 6532 & 22 & 78 & $2,804,489$ \\
\hline Cameroon* & 2011 & DHS & 5033 & 41 & 59 & $3,509,789$ \\
\hline Central African Republic* & 2010 & MICS & 10,141 & 32 & 68 & 645,937 \\
\hline Chad & 2004 & DHS & 4303 & 44 & 56 & $1,950,392$ \\
\hline Chad $^{*}$ & 2010 & MICS & 12,325 & 40 & 60 & $2,291,967$ \\
\hline Congo (Brazzaville)* & 2012 & DHS & 4253 & 25 & 75 & 722,068 \\
\hline Congo Democratic Republic* & 2010 & MICS & 10,370 & 38 & 62 & $11,180,259$ \\
\hline Cote d'Ivoire* & 2011 & DHS & 3200 & 33 & 67 & $2,997,145$ \\
\hline Gabon* & 2012 & DHS & 3281 & 61 & 39 & 238,066 \\
\hline Ghana & 2003 & DHS & 3088 & 27 & 73 & $3,039,525$ \\
\hline Ghana* & 2008 & DHS & 2379 & 33 & 67 & $3,423,057$ \\
\hline Guinea* & 2012 & DHS & 3085 & 28 & 72 & $1,856,269$ \\
\hline Mali & 2001 & DHS & 9359 & 21 & 79 & $1,993,192$ \\
\hline Mali & 2006 & DHS & 10,778 & 30 & 70 & $2,353,057$ \\
\hline Mali* & 2012 & DHS & 4313 & 25 & 75 & $2,864,503$ \\
\hline Mauritania* & 2011 & MICS & 8175 & 36 & 64 & 564,774 \\
\hline Niger* & 2012 & DHS & 4771 & 22 & 78 & $3,556,852$ \\
\hline Nigeria & 2003 & DHS & 4282 & 37 & 63 & $23,002,853$ \\
\hline Nigeria* & 2008 & DHS & 19,010 & 29 & 71 & $26,499,513$ \\
\hline Senegal & 2005 & DHS & 2753 & 32 & 68 & $1,911,151$ \\
\hline Senegal* & 2010 & DHS & 3445 & 30 & 70 & $2,188,960$ \\
\hline Sierra Leone & 2005 & MICS & 4144 & 25 & 75 & 864,591 \\
\hline Sierra Leone* & 2010 & MICS & 7518 & 29 & 71 & 915,492 \\
\hline Togo* & 2010 & MICS & 4624 & 24 & 76 & $1,020,492$ \\
\hline
\end{tabular}

Samples with * used for the 2010 regional estimate 
fell slightly, but there was a consistent base for comparison. To ensure comparability between country estimates we only consider data collected on children aged 0 to 4 years. A small minority of surveys only sampled children aged 0-2 years; we argue that where possible estimates from populations with the same age range should be compared, as rates of malnutrition based on a $0-4$ population will be higher than those based on a $0-2$ population, given that rates increase once children stop breastfeeding. In total, the sample included data on just over 183,000 children in West and Central Africa.

The analysis presented in this paper is a simple trend analysis of malnutrition rates and variation of these rates across different groups and countries, adjusting for the relevant stratification, clustering and post-stratification weights. To show the risk of malnutrition across different types of households and provide an overview of the composition of malnourished children, we use information on the education of the mother/carer, and from the household asset-based wealth index. We also use UNHABITAT's criteria to identify households living in slum-like conditions (i.e. households using unimproved sources of water and forms of sanitation, and dwellings of poor quality i.e. mud floors). These cover only part of the UN-HABITAT definition, but full data on overcrowding and tenure were only available for a minority of countries. Finally, we also use DHS-provided subnational rates of mortality for the same period to look at the correlation between malnutrition and mortality. The mortality rates (age 1 to 4 ) are calculated by using a synthetic cohort life table approach described by Pullum et al. (2013).

\section{Results}

The aim of this paper is to detail the prevalence and patterning of malnutrition in young children in West and Central Africa. In doing so, we present rates of malnutrition using the conventional indicators of stunting and wasting, the CIAF, and a summary measure of Multiple Malnutrition (MM). Estimates of the numbers of children affected were derived by applying post-stratification population weights which adjust samples to reflect the ages and sex composition of the child population for each country. Population data are taken from the United Nations' World Population Prospects database (2012).

\subsection{Extent of Malnutrition}

Table 3 presents regional and national estimates of the prevalence, and number, of malnourished children under 5 in west and central Africa in 2010, using Stunting, Wasting, the CIAF and the MM summary measure. These data can be used to show the numbers of malnourished children 'missed' when stunting and wasting are used singly.

For example, the CIAF shows that nearly half (48\%) of all children under 5 experience some form of malnutrition (CIAF), compared to Stunting (38\%), Wasting $(12 \%)$ and Underweight (23\%). In terms of numbers of malnourished children in the region, the CIAF estimates the figure to be 33 million children compared to 26 million by Stunting, 15 million by Underweight and 8 million by Wasting. This difference of between 6.5 million (CIAF minus Stunting) and 25 million (CIAF minus Wasting) 


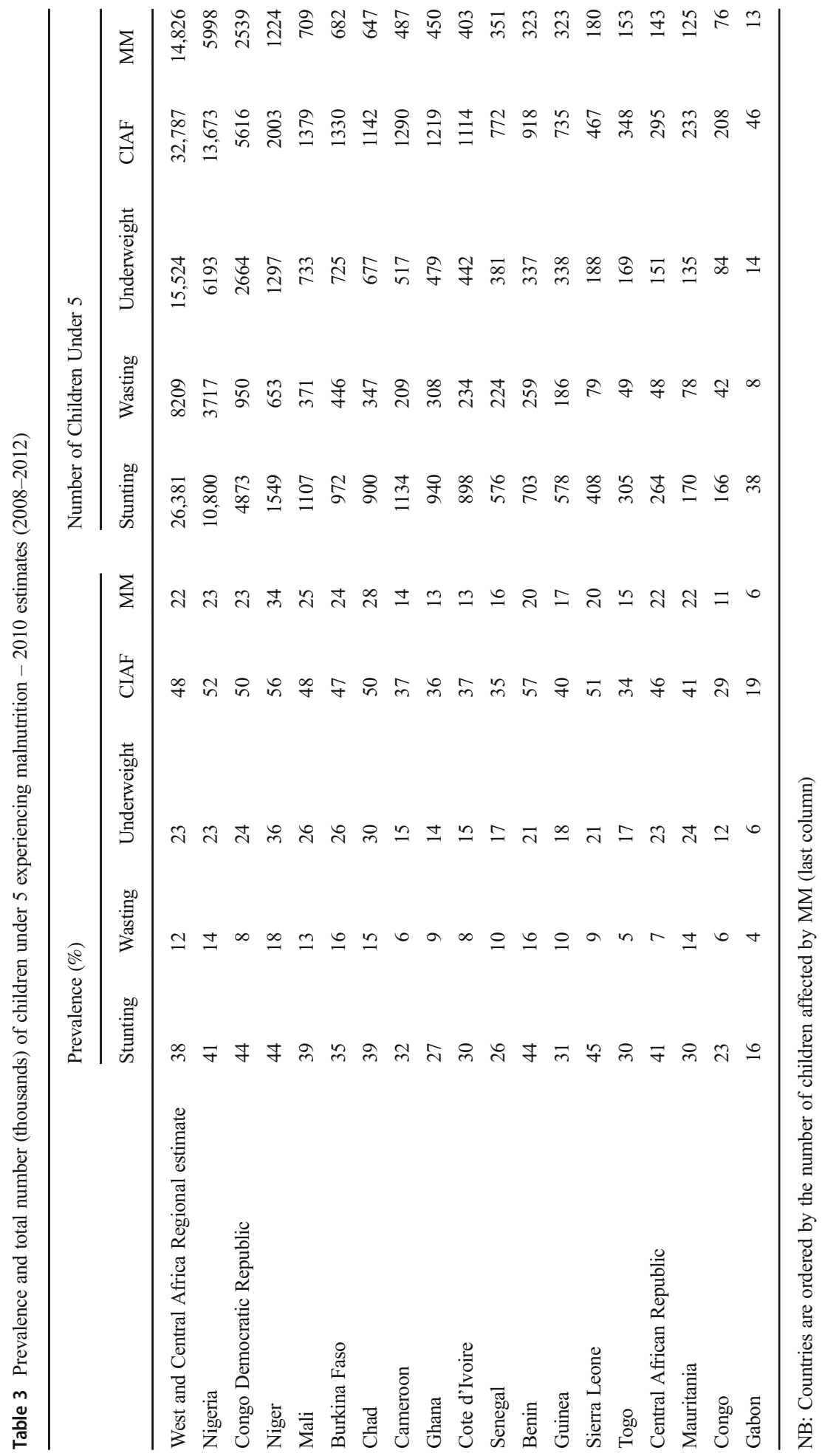


children means reporting on progress towards the SDGs using Stunting and Wasting will miss millions of children.

The CIAF shows that in all but one country (Gabon, 19\%), between one in three and one in two children were malnourished in 2010; over half of all children in Benin (57\%), Niger (56\%), Nigeria (52\%), Chad (50\%) and the Democratic Republic of Congo (50\%) experienced one or more forms of malnutrition. One country, Nigeria, due to its size dominates regional estimates, and determines regional success or failure in meeting international targets like the SDGs. With 13.5 million malnourished children, Nigeria accounts for nearly half of the regional total (33.2 million). This disparity can be displayed effectively using cartograms. In Fig. 1 the land area for every country reflects the number of malnourished children (using the CIAF). The different colours represent the varying prevalence rates of CIAF malnutrition among children.

\subsection{Disaggregating Malnutrition}

The CIAF can be used in a disaggregated form, to show how malnutrition is patterned across a population of children. This is useful, as research discussed above has shown that different combinations of malnutrition can have quite different outcomes for the health and survival of children. Knowing how many children are affected by a double or triple anthropometric failure can provide policy makers with a measure of the seriousness of the challenge faced. Table 4 presents prevalence rates and numbers of children in each of the disaggregated groups, at national and regional level. For the

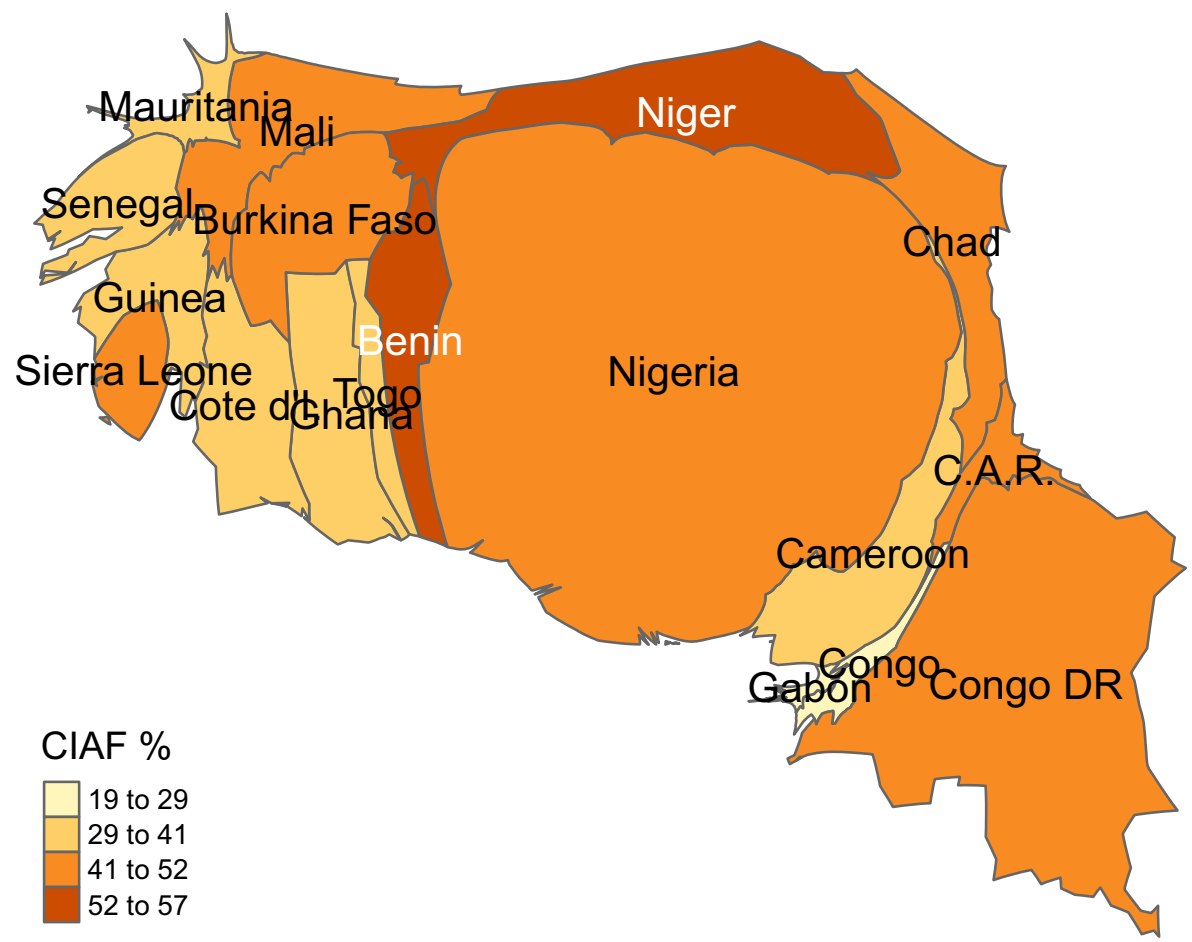

Fig. 1 Cartogram of malnutrition among children under 5 in West and Central Africa - 2010 estimates (2008-2012) 
purposes of this paper we omit figures on overweight and obesity as less than $2 \%$ of our sample are obese and less than $1 \%$ of the disaggregated anthropometric failures in Table 4 are overweight.

\subsection{Multiple Malnutrition}

Figure 2 represents the overlap between Stunting, Underweight and Wasting at the regional level, showing how groups of children are missed when the measures are used singly.

While just over half (52\%) of all children in West and Central Africa do not experience any form of malnutrition, this still leaves significant numbers affected. Around a quarter of children in the region experience a single anthropometric failure (i.e. 'only' Stunting, Wasting or Underweight), with the remaining 22\% experiencing multiple failures, or multiple malnutrition (MM). Overall, in 20102.5 million children (4\%) experienced a triple failure, 2.8 million children experienced Wasting and Underweight (4\%), while nearly 10 million children (14\%) experience both Stunting and Underweight. Given the raised risks of premature mortality highlighted by research, this could be a contributing factor to the region's high rates of under 5 mortality. Countries with higher rates of single failure generally tend to have higher rates of multiple failure, although the relationship is not linear, with some countries exhibiting high levels of multiple failure alongside average levels of single failure (e.g. 35\% and $22 \%$ respectively in Niger); other countries may exhibit high levels of single failure and only average levels of multiple failure, such as Benin (38\% and 20\%). At the regional level Stunting and Underweight contribute most to MM, accounting for over $60 \%$, with Wasting and Underweight and the triple failure group accounting for the rest (see Table 5. The same information on individual country composition can be created by combining information in Tables 3 and 4).

Studies like McDonald et al. (2013) which examine the relationship between malnutrition and mortality have relied on large cohort studies and randomized trials data, which are most suited for showing increased mortality among children experiencing MM. We wanted to explore whether similar relationships (between patterns of malnutrition and mortality) could be observed at an area level. We used DHS-and MICS-provided child mortality estimates, at national and sub-national level, for the period 2000-2010, and linked them to our sample of child-level anthropometric data, to explore the relationship between anthropometric failure and mean child mortality rates. The results of this analysis are shown in Fig. 3 along with Pearson's and Spearman's correlations for sub-national estimates. These results confirm the analysis by McDonald et al. (2013). Combined (double and triple) failure indicators show the highest levels of correlation with mortality (Spearman's rank correlation of 0.7 ), and single failure indicators show much lower levels of correlation ( 0.4 or below). The main difference between our results and McDonald et al.'s is that we find a weaker correlation between wasting and underweight and mortality, but overall both analyses suggest the importance of prioritising children and areas with combined forms of malnutrition. The same analysis was repeated using national estimates, with very similar results (not shown).

Table 3 (and Fig. 2) reveal that the overlap between MM and Underweight is considerable, given that (almost by definition) children who experience both Stunting and Wasting are invariably going to be Underweight. This means that all children who 


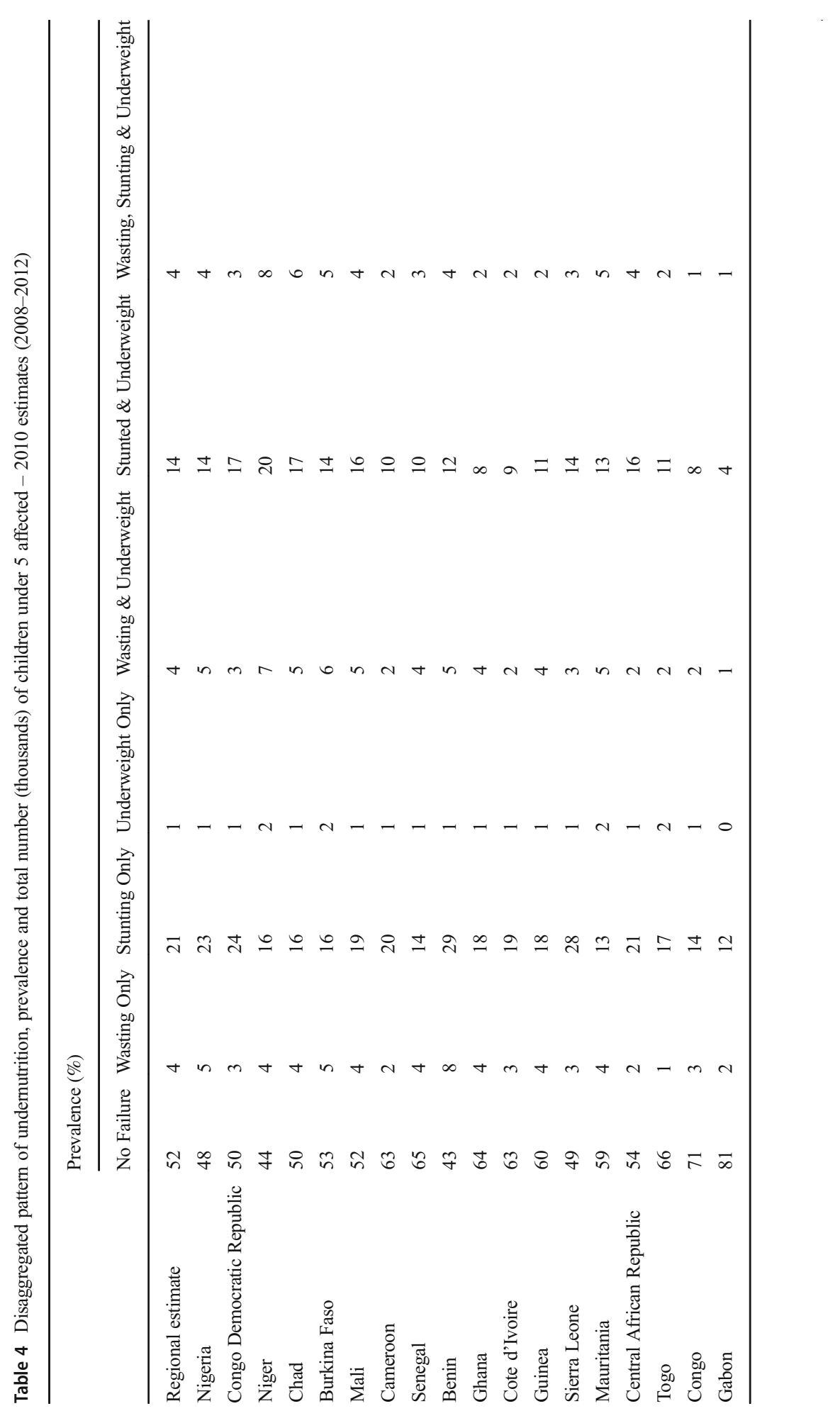


तิં

ڤू̆

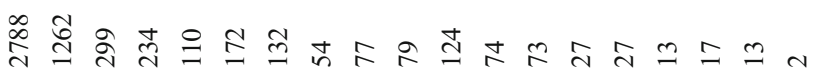

공

若

迹

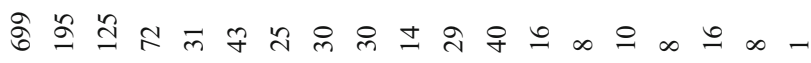

咅

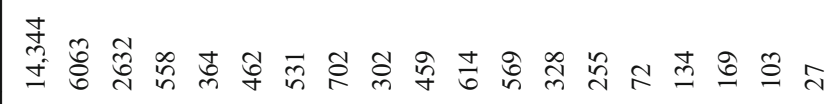

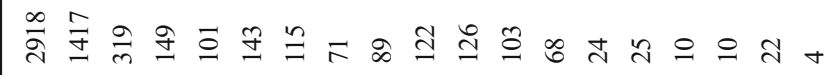

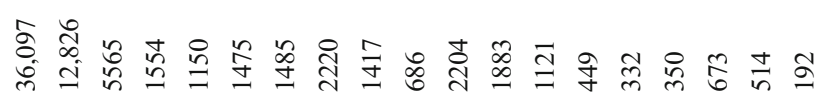

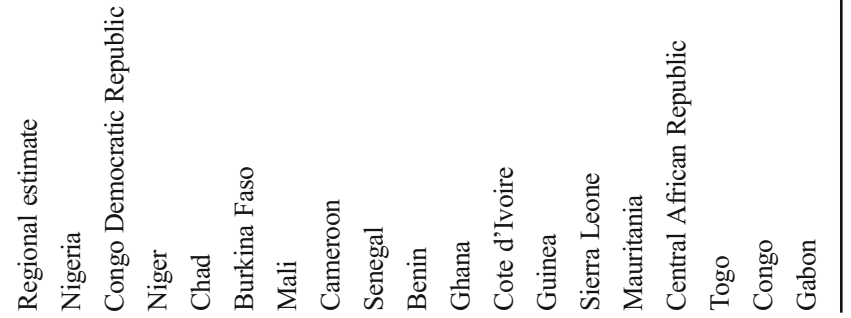




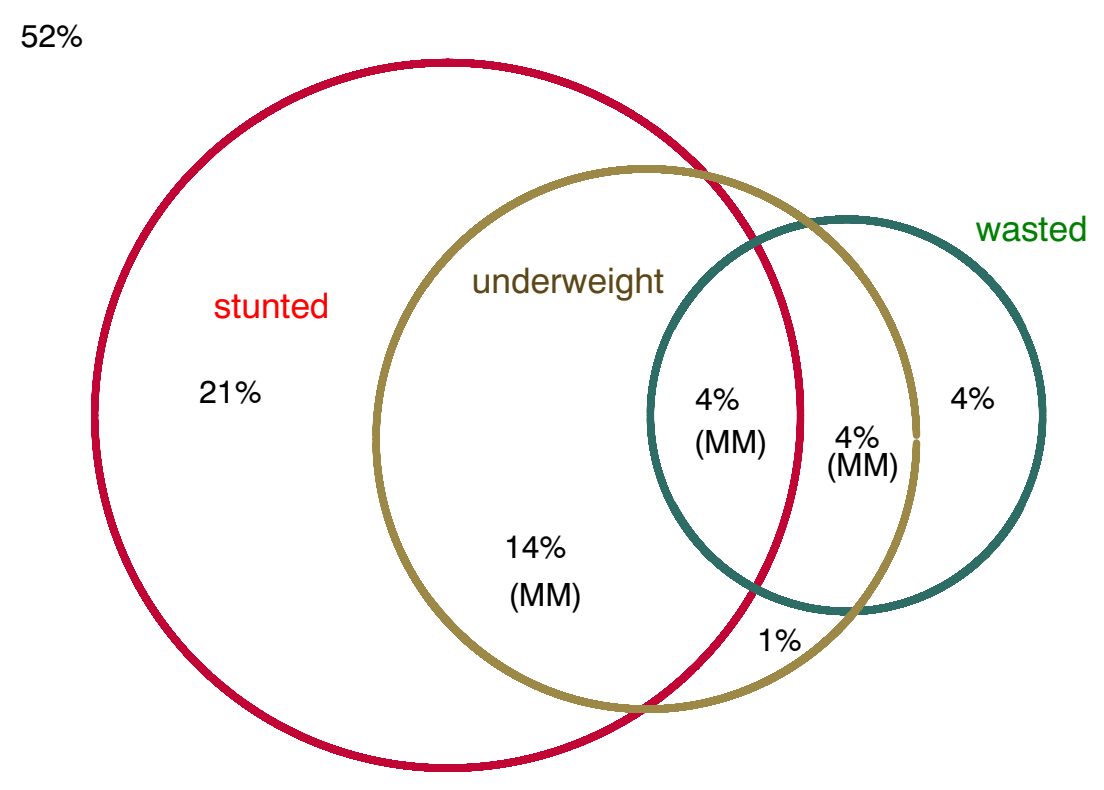

Fig. 2 Overlaps between types of anthropometric failure among children under 5, Central and West Africa Region - 2010 Estimates (2008-2012)

are both Stunted and Wasted are also Underweight. As the percentage of Underweight only children is small (roughly $1 \%$, see Table 4), at an aggregate level this leads to an almost complete overlap between rates of MM and Underweight (see Table 3). We argue that MM provides a better indicator of children experiencing combined forms of anthropometric failure, who have higher mortality and morbidity risks. The exclusion of children who are "Underweight only" makes MM a better indicator of combined malnutrition and represents a judicious compromise between using Wasting and Stunting separately and considering only children with a triple failure. Providing an in-depth analysis of the latter proves problematic, particularly in sub-Saharan Africa where the low prevalence of triple failure (mostly between $2 \%$ and 4\%), combined with the small sample size lead to large margins of error, even at the national level. Moreover, focusing only on the percentage experiencing both Stunting and Wasting

Table 5 Composition of multiple malnutrition of children under 5, Central and West Africa Region- 2010 estimates (2008-2012)

\begin{tabular}{lll}
\hline & $\%$ & Share of all multiply malnourished \\
\hline Wasting \& Underweight & 4 & 18 \\
Wasting, Stunting \& Underweight & 4 & 18 \\
Stunted \& Underweight & 14 & 64 \\
Total (Multiple Malnutrition) & 22 & 100 \\
\hline
\end{tabular}




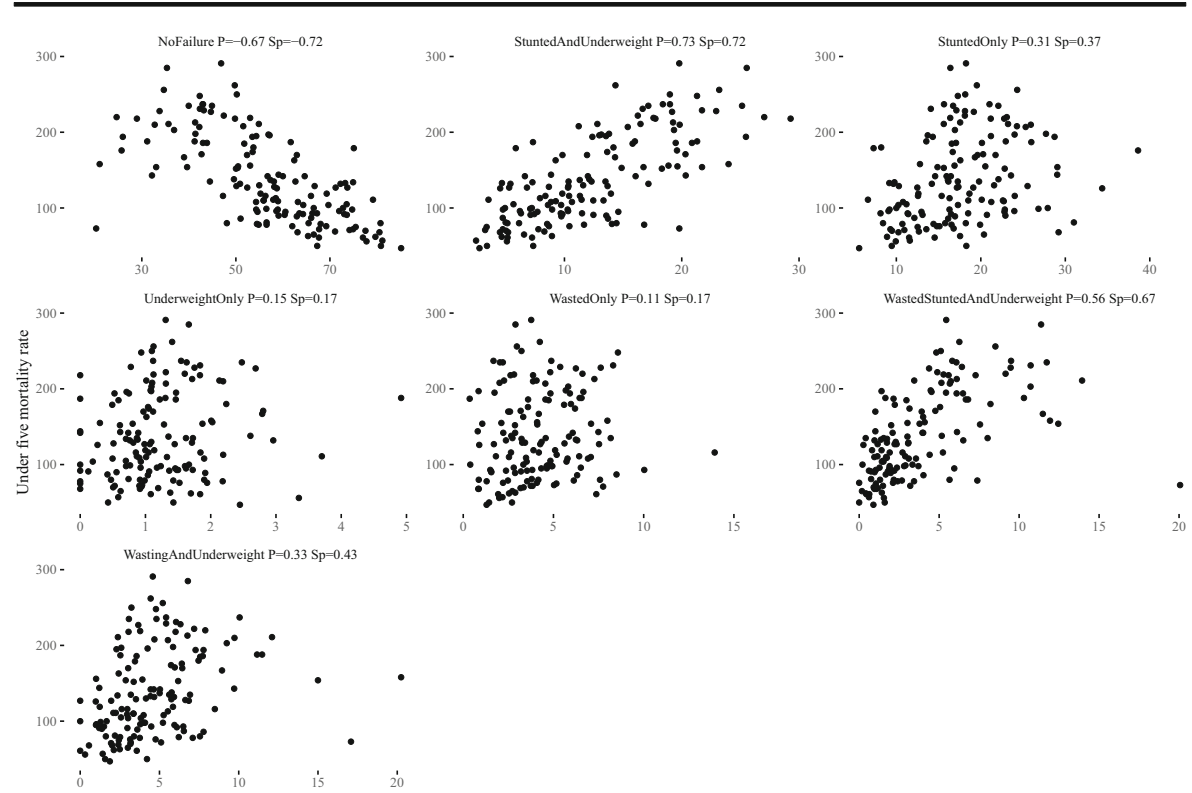

Fig. 3 Relationship between regional child mortality and disaggregated nutritional status for children under 5 . 95\% confidence intervals, West and Central Africa Region

(Khara et al., 2017) underestimates the extent of multiple malnutrition by omitting children who experience Underweight and Stunting (but not Wasting), who account for $14 \%$ of all children in the region. Similarly, another $4 \%$ of children are wasted and underweight (but not stunted). As shown by McDonald et al. (2013) and our area level analysis, these children also have greater risk of mortality and morbidity.

To reiterate our point, all those who are wasted and stunted are by definition also underweight (see Fig. 2) and therefore focusing on children who are both wasted and stunted is equivalent to focusing on children experiencing a triple failure. However, focusing only on stunting and wasting either singly or combined misses out a substantial number of children who are either wasted and underweight $(4 \%)$ or stunted and underweight (14\%), which in Sub-Saharan Africa accounts for $18 \%$ of children. These children have substantially higher rates of morbidity and mortality (McDonald et al. 2013), not as high as for those with triple failure but still considerably higher than those with a single anthropometric failure. These findings, represented in Fig. 4, can also be corroborated by looking at the risk of diarrhoea.

Figure 5 shows that children who are simultaneously stunted and underweight (group E) or simultaneously wasted and underweight (group C) are more likely to have had diarrhoea in the last two weeks than children who are stunted only or wasted only and less likely than those who are wasted and stunted (and therefore underweight).

Overall, the analysis above confirms the importance of considering whether the child is underweight, specifically whether the child is underweight and stunted, or underweight and wasted. We also find some evidence that those who are stunted and 


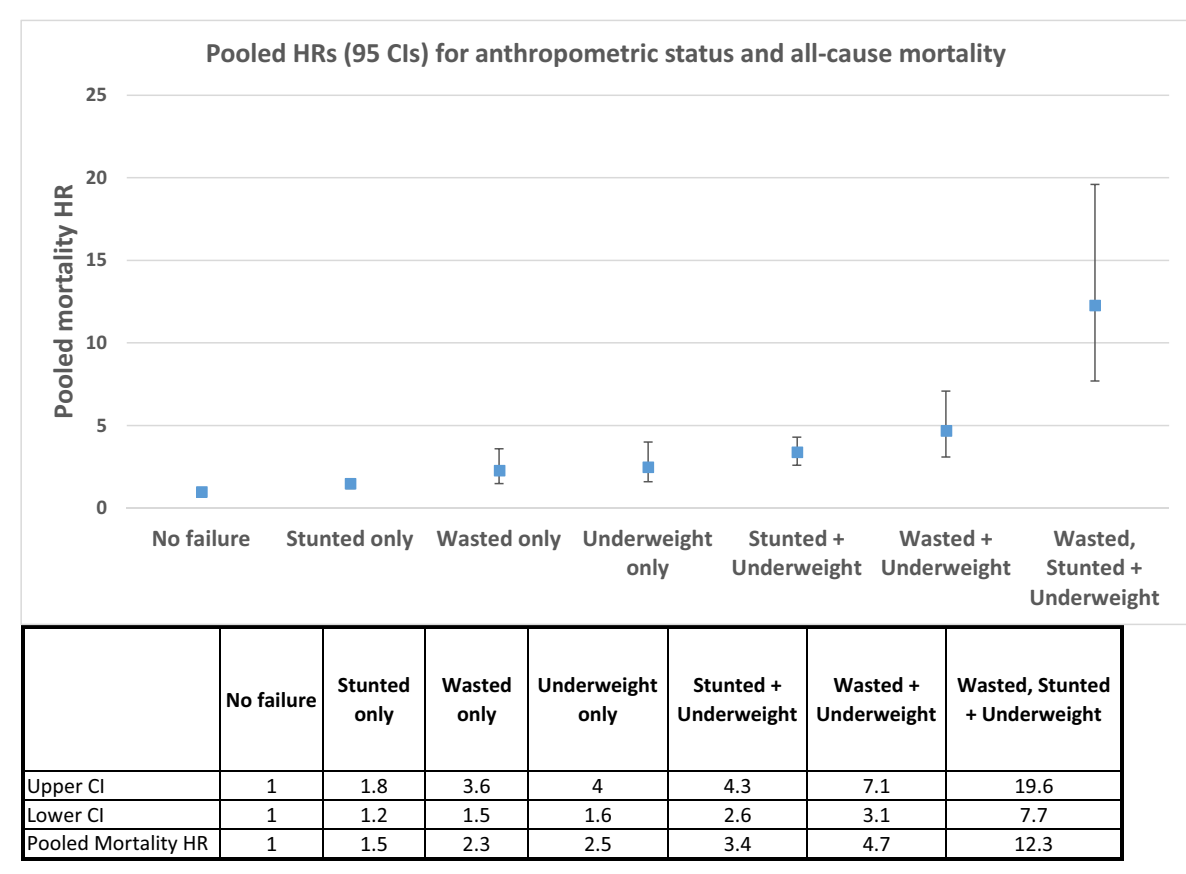

Fig. 4 Pooled HRs (95\% Cis) of all-cause mortality by disaggregated nutritional status (Graphical representation of results from McDonald et al. (2013))

underweight for example are more likely to be severely stunted than those who are only stunted. Similarly, those who are wasted and underweight are more likely to experience severe wasting. Figure 6 for example shows children who are both stunted and underweight as opposed to only stunted are more than twice as likely to have a height

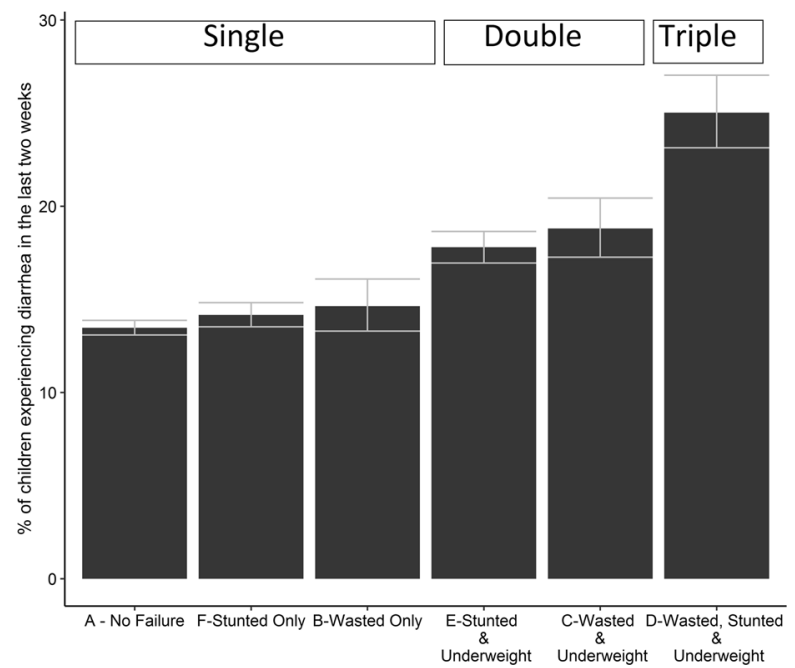

Fig. 5 Percentage of children under 5 with diarrhoea in the last two weeks by Anthropometric Failure. Note: children who were underweight only were omitted as they represent only $1 \%$ of the sample. $95 \%$ Confidence Intervals, West and Central Africa Region - 2010 Estimates (2008-2012) 
for age below 3.5 standard deviations. Overall those experiencing double failure are more concentrated in the left side of the WHO standardised scores distribution.

\subsection{Drivers of CIAF and MM}

Figure 7 (top pane) confirms that the probability of malnutrition is strongly correlated with poverty (here measured using the household asset Index, household living conditions (reflecting the UN-HABITAT definition of a slum), and maternal education.

Regardless of the indicator, children with a higher socio-economic status have much lower risks of malnutrition compared children in worse-off

\section{F- Stunted Only E- Stunted and Underweight (not wasted)}

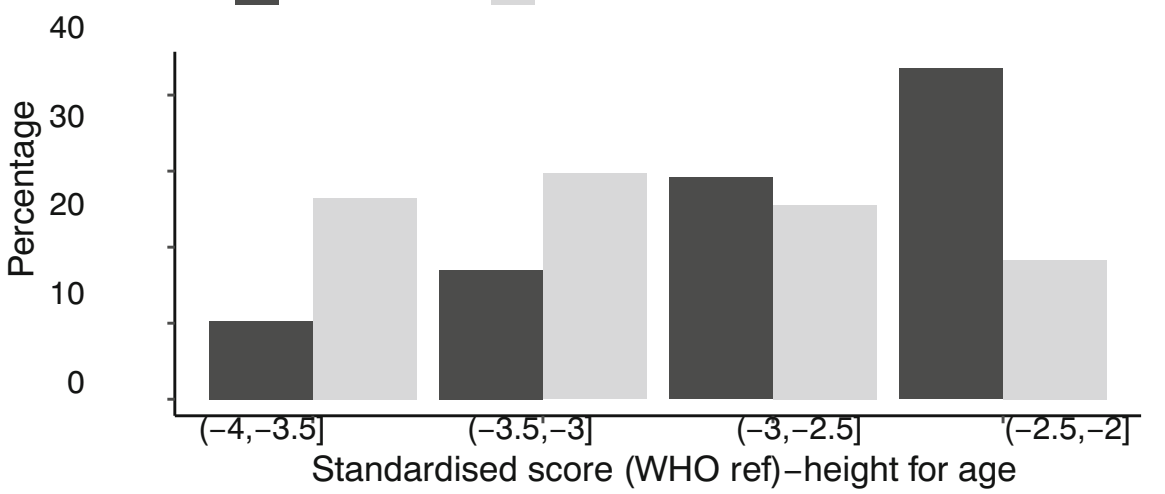

B-Wasted Only E-Wasted and Underweight (not stunted)

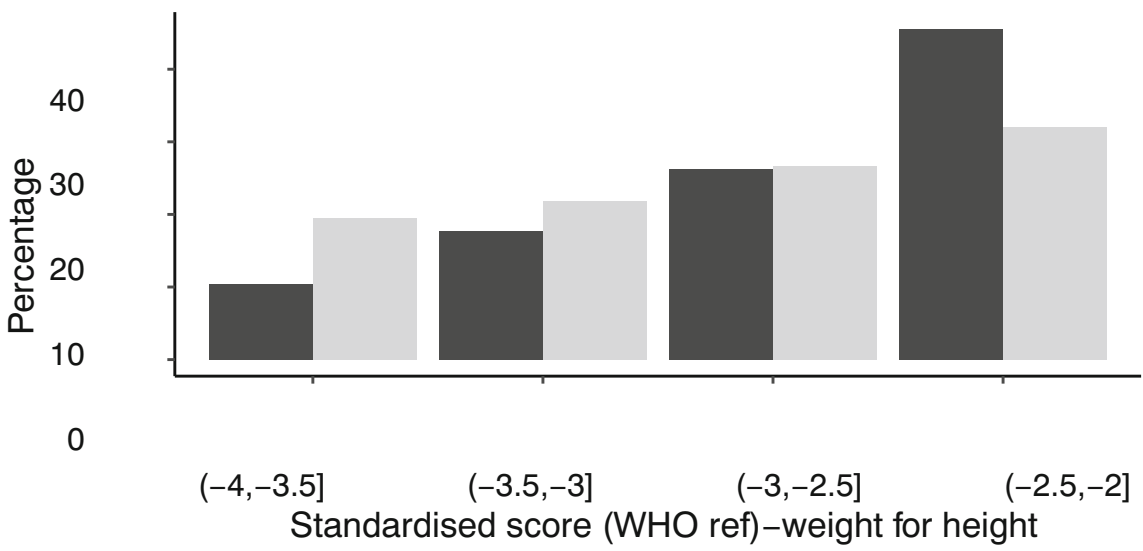

Fig. 6 Percentage of children under 5 with a given standardised Z-score range according to whether they experience single or double failure. Top pane shows children with stunting, bottom pane shows children with wasting. West and Central Africa Region - 2010 Estimates (2008-2012) 

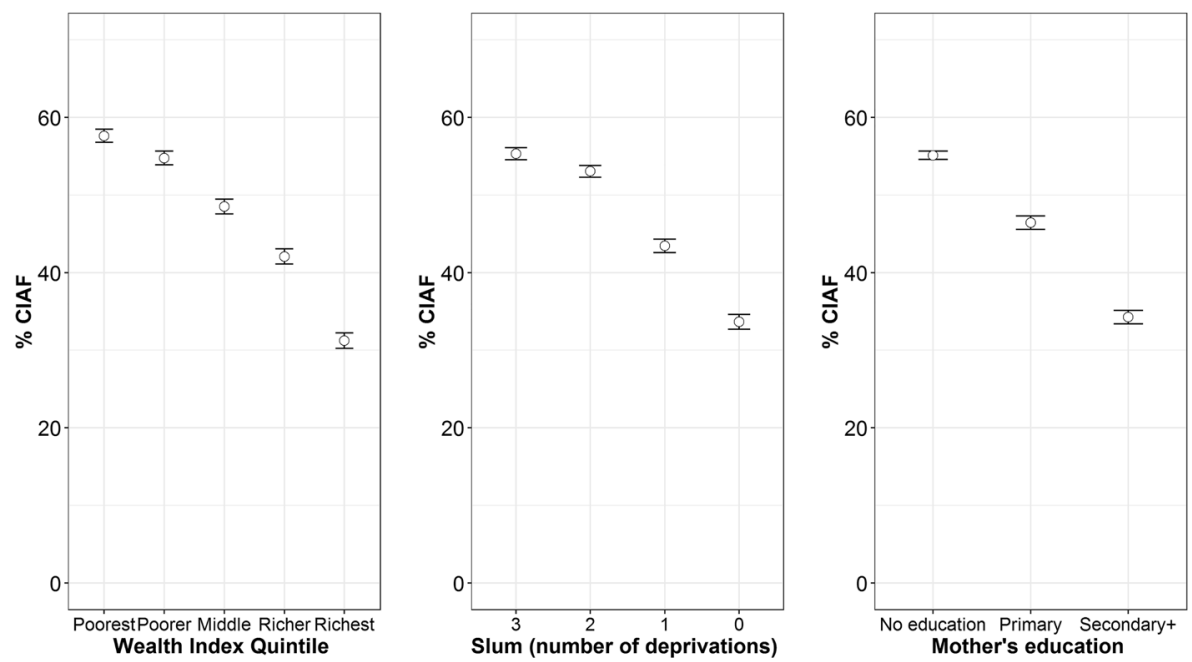

- Urban - Rural
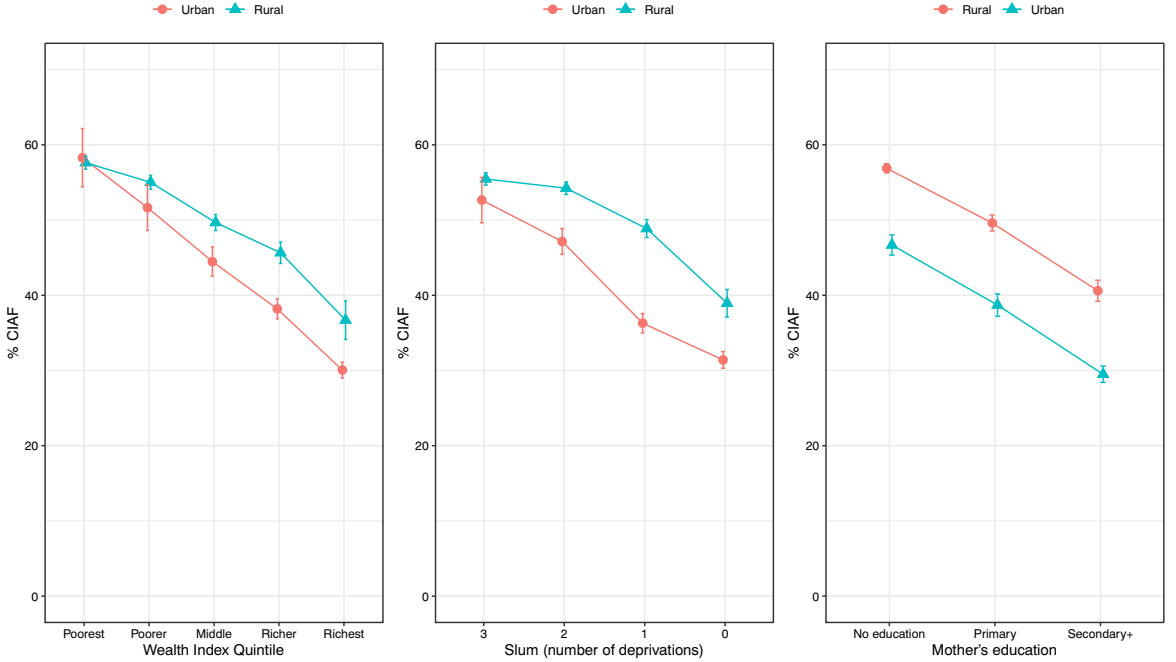

Fig. 7 Decomposition of CIAF by asset Index, deprivation of living conditions and maternal education for children under 5, with 95\% confidence intervals, West and Central Africa Region - 2010 estimates (2008-2012)

households. The bottom pane confirms that this association is consistent across urban and rural areas and that children living in urban and rural areas have different rates of malnutrition but that overall the poorest and those with no access to water, improved floor or toilets in rural and urban areas have similar chances of being malnourished. When decomposing the CIAF (see Fig. 8), we see that children in the richest $20 \%$ of households have considerably lower rates of Stunting (particularly Stunting only and Stunting and Underweight), and lower rates of MM.

The risk of triple failure among children in wealthier households is half that of the poorest households ( $2.5 \%$ and $5 \%$ respectively). The only two indicators which do not 

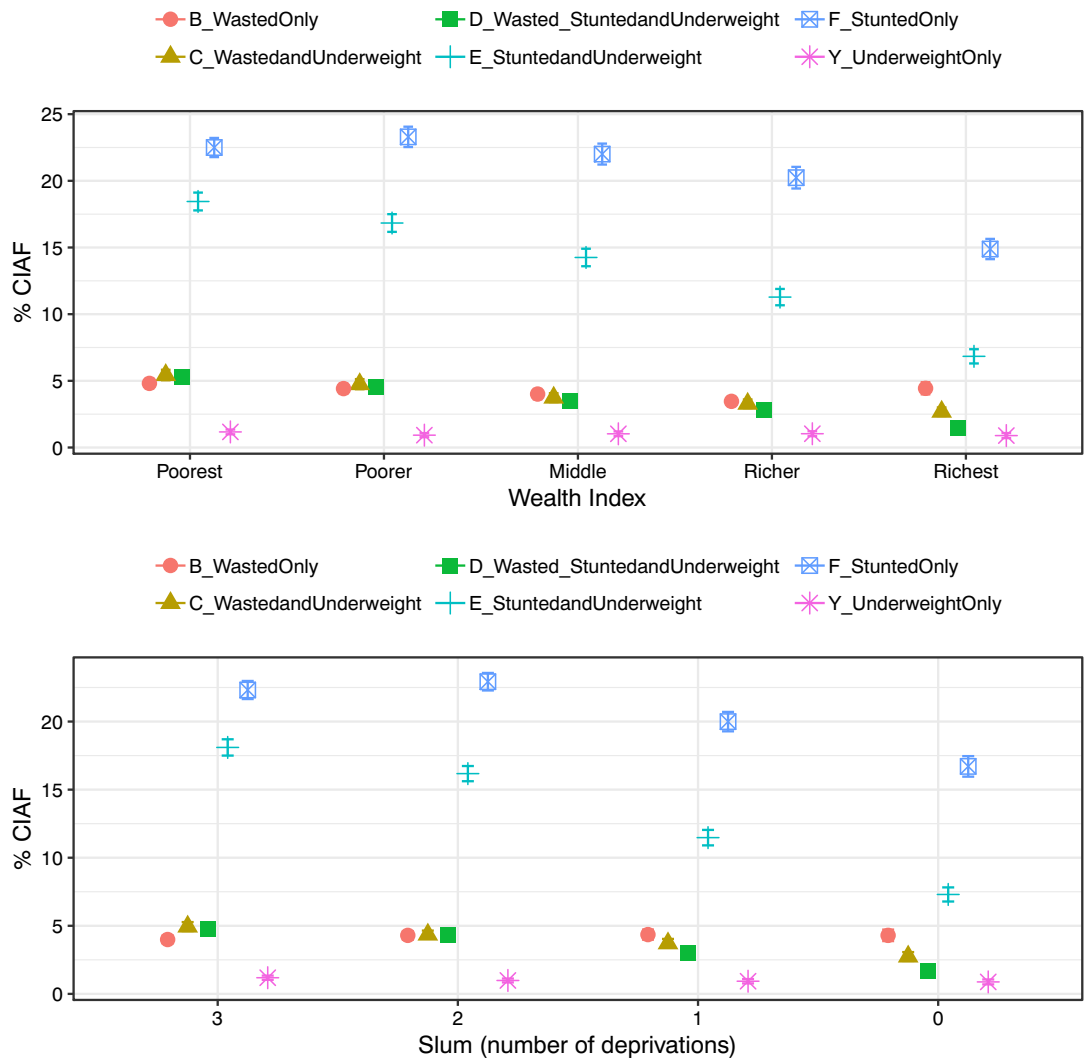

Fig. 8 Disaggregation of CIAF for children under 5 by asset index and deprivation of living conditions with 95\% confidence intervals, West and Central Africa Region - 2010 estimates (2008-2012)

show a clear socio-economic gradient are Wasting only and Underweight only. All other forms of combined failure which include Wasting and Underweight show a clear socio-economic gradient.

\subsection{Change over Time}

Given the attention international development targets like the MDGs placed on poverty and malnutrition across the 2000 s, it is somewhat disheartening to see that relatively little progress was made at the aggregate level for the West and Central Africa region. Table 6 shows there was no effective reduction in the percentage of children experiencing one or more failures (CIAF) between 2000 and 2005 and 2006-2010; there was also very little change with regards the prevalence of single or multiple malnutrition during this period. Combined with high population growth, this means there were more children (in absolute terms) with anthropometric failure in 2010 (21 million) than in 2005 (18 million), and greater numbers experiencing either double or triple failure. One positive statistic is that there were 21.4 million children in the region who didn't experience any failures, up from 18.3 million from the 2000-2005 period. 
Table 6 Change over time of aggregate and multiple malnutrition (number in millions and percentages of children under 5), Central and West Africa Region

Number and Proportion of Children under 5 experiencing:

2000-2005

$18(50 \%)$

$8,6(24 \%)$

$1,5(4 \%)$

$18,3(50 \%)$
2006-2010

$21(49 \%)$

$9,2(22 \%)$

$1,6(4 \%)$

$21,4(51 \%)$

To understand why so little progress was made in reducing malnutrition in the region, it helps to know where the malnourished children live. Mapping prevalence and numbers of children affected is one way to do this, but the data can also be decomposed to see how children from certain areas (e.g. urban and rural) or social groups (e.g. children living in 'slum-like' conditions, in either urban or rural areas) contribute to changes in malnutrition estimates. Figure 9 decomposes the changing number of malnourished children in the region by where they live and the type of living conditions they experience.

Of the 2.46 million extra malnourished children in 2010, most (58\%, 1.4 million) lived in rural areas, which is what other analyses generally suggest (Smith et al., 2005),

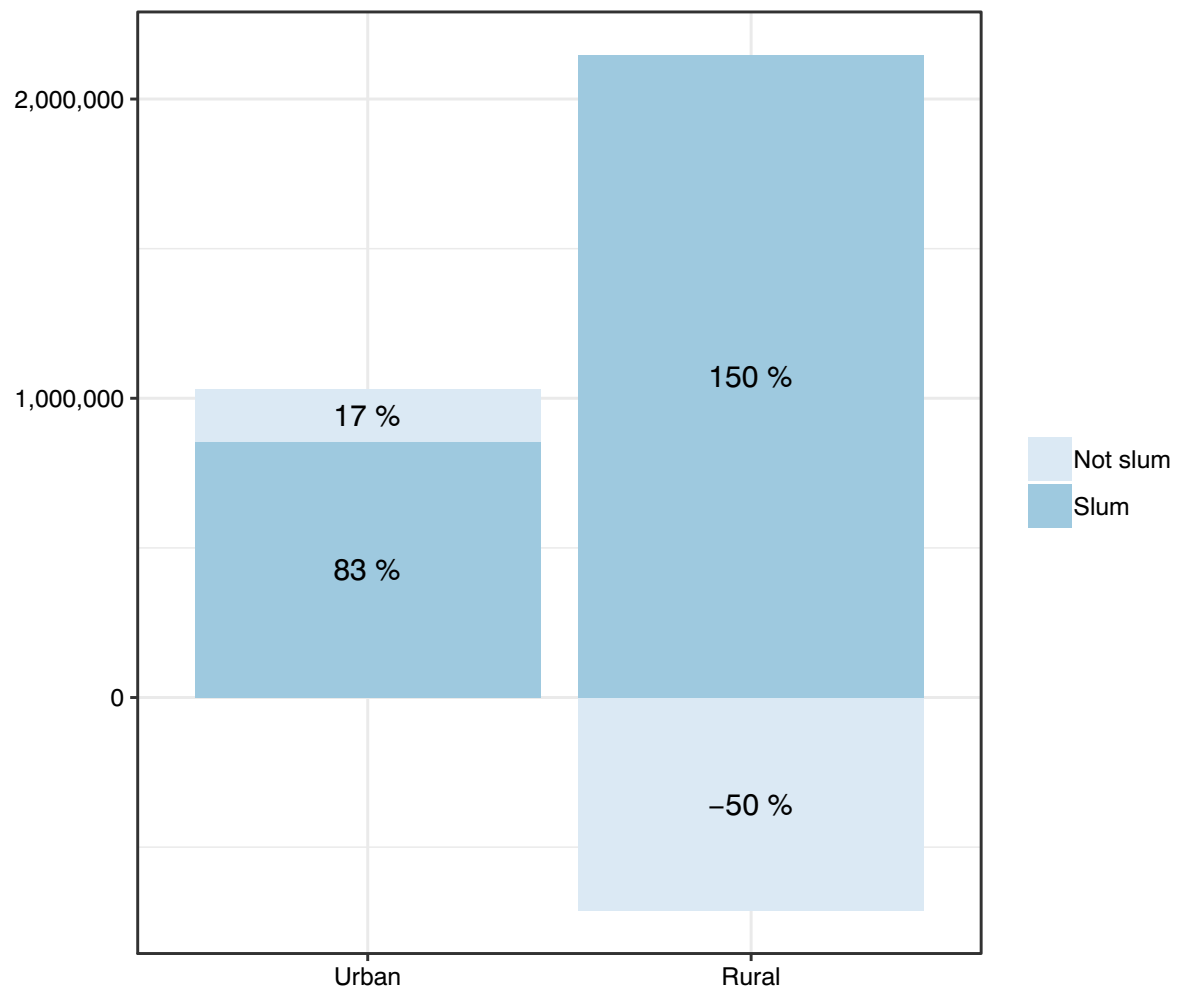

Fig. 9 Decomposition of change in CIAF among urban and rural children under 5, West and Central Africa Region 
but there were also substantial increases in the number of malnourished urban children, who accounted for 1 million of the additional 2.46 million children in the region. As shown in Fig. 9, the increase in the number of malnourished rural children was completely accounted for by children living in slum-like conditions.

This may not come as a surprise since over $75 \%$ of rural households in the sample reported a lack of access to either water or sanitation or lived in dwellings with mud flooring. What is less known is that roughly $50 \%$ or urban households in the sample reported living in slum-like conditions, and that children in these households accounted for $83 \%$ of the increase in malnourished urban children. Urban areas are witnessing considerable increases in the number of malnourished children, with most of this increase occurring among the urban poor. In 2003, UN-HABITAT reported that $72 \%$ (166.2 million people) of the urban population of Sub-Saharan Africa (SSA) lived in slum-like conditions (UN-HABITAT, 2003); in 2014 this proportion had declined to $55 \%$, but in terms of numbers, the number of people living in urban slums had risen (in SSA) to 201 million (UN-HABITAT, 2016). These demographic changes, combined with clear evidence that malnutrition is a growing challenge in urban areas, suggests efforts to meet the 2030 SDG nutrition targets need scaling up if they are to have any chance of success.

\subsection{National-Level Trends}

For countries with multiple surveys, we now present an analysis of trends in aggregate (CIAF) and multiple malnutrition. Regional analyses are dominated by Nigeria, given the size of its population, so it is important to highlight positive stories which might otherwise be missed. We disaggregate the results by urban and rural areas, to show whether the patterns are similar in terms of progress, or whether it is the case that some groups are left behind. This also allows us to further corroborate the compositional analysis findings above. We have also enlarged the period of analysis, to minimise the risk of over-interpreting trends within the last decade. Figures 10 and 11 show the trends in aggregate (CIAF) and multiple malnutrition observed for Benin, Burkina Faso, Cameroon, Cote d'Ivoire, Ghana, Guinea, Mali, Niger and Nigeria, for the period 1990 to 2015. Rates are shown in the top panes, while totals are shown in the bottom panes.

Overall, the picture is a mixed one. In Benin, for example, following an initial decline in malnutrition prevalence, there was a consistent increase from the year 2000 to 2015 , for both urban and rural children. In Burkina Faso, there was no significant change in the prevalence of urban malnutrition, but between 2000 and 2015, rural malnutrition rates fell significantly. In Ghana, statistically significant falls in malnutrition were observed for both urban and rural areas, between 2000 and 2015, enabling it to have the lowest rates in the region. Ghana was the only country for which there was a decline in the number of malnourished children between 2000 and 2015. Impressive reductions also occurred during the 2000s in Guinea, Mali and Niger. By contrast, in the case of Nigeria, there were no statistically significant changes (reductions) in the prevalence of malnutrition, and so with population growth, this resulted in large increases in the number of children affected, in both urban and rural areas. Rates of aggregate malnutrition in 2010 were at or above $30 \%$ for most countries in the region, with rates above $50 \%$ for rural children in Benin, Burkina Faso, Mali, Niger and 
-Urban= - Rural

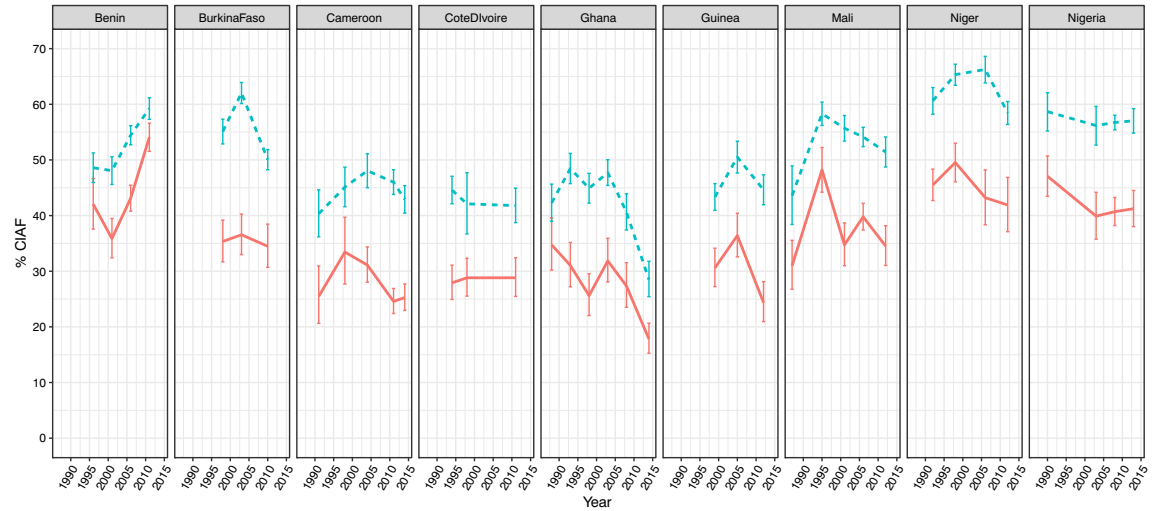

-Urban- = Rural

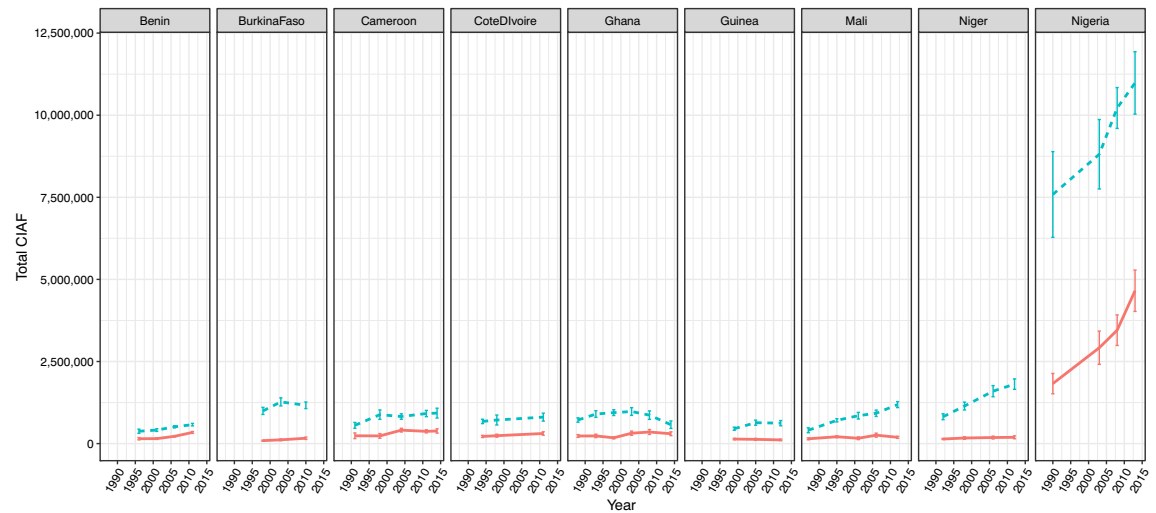

Fig. 10 Percentage (top) and number of children (bottom) under 5 with anthropometric failure by urban and rural residence (CIAF) - 95\% confidence intervals

Nigeria. These high rates meant that in each of these countries, the numbers of children affected were higher than in 1990 and 2000.

There is limited evidence that rural and urban areas are following different trajectories, except for countries like Burkina Faso and Niger, where rural areas with very high rates of rural CIAF and MM have seen some remarkable improvements (between 5 and 10 percentage points decrease), with fewer/less impressive changes in urban areas. In Cameroon there has been a clear widening of disparities between urban and rural areas, whereas Benin stands out as the one country which saw sustained increases in both CIAF and MM in 2000-2015 period. Ghana halved the percentage of stunted and wasted children between 1998 and 2014, which has meant that MM has also been cut, from 18\% to $9 \%$.

\section{Discussion}

Following the first ever analysis of aggregate malnutrition (Nandy et al. 2005) and the realisation that different combinations of deficits entailed different mortality (McDonald 

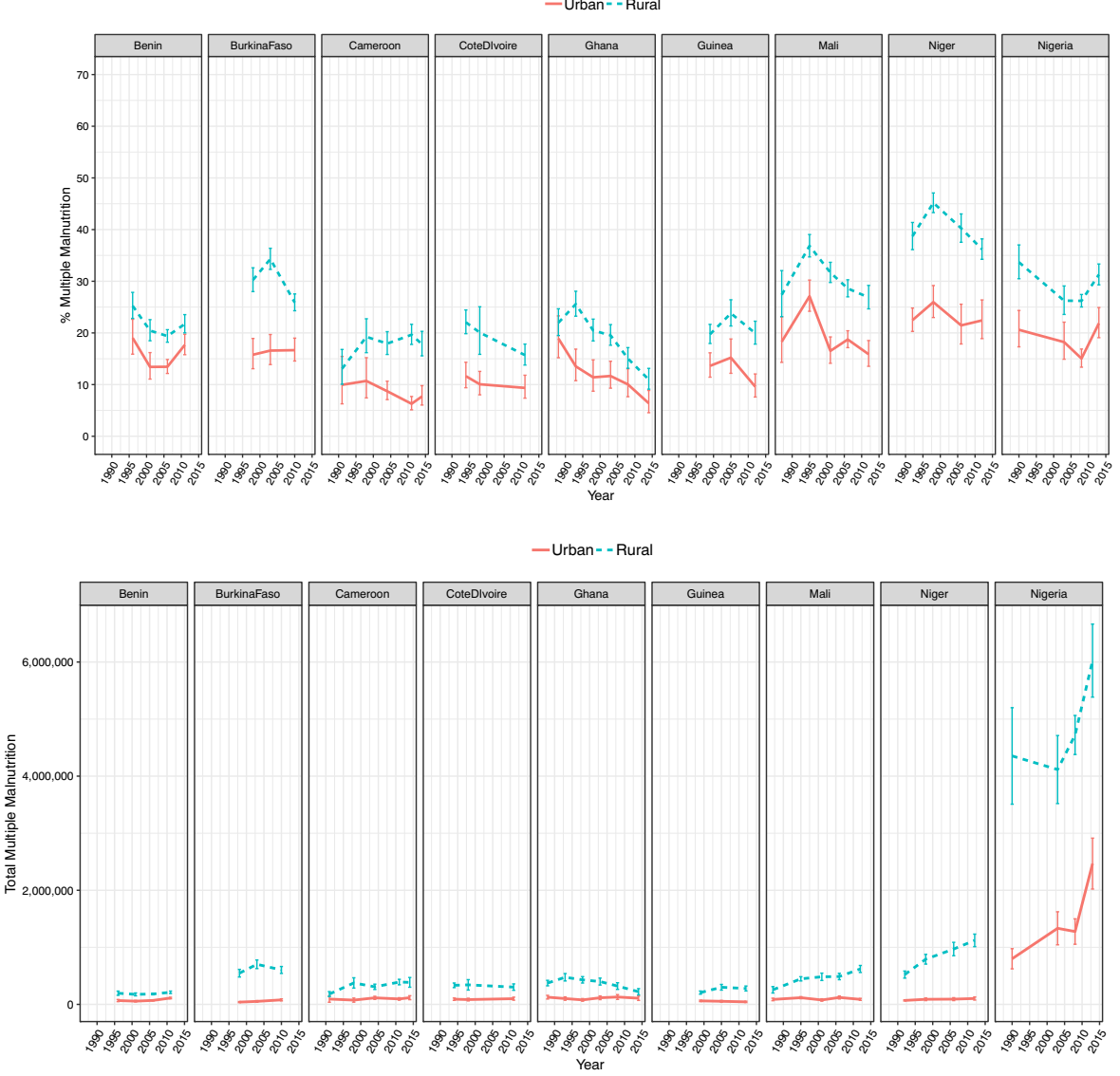

Fig. 11 Percentage (top) and number of children under 5 (bottom pane) experiencing multiple malnutrition $95 \%$ confidence intervals

et al. 2013), there is growing recognition of the need to reflect how malnutrition is patterned across societies, with researchers now doing this (Briend et al. 2015; Khara et al., 2017; Myatt et al. 2018). The data set out in this paper show there is a clear need to present the full picture of the extent of malnutrition, using a measure like the CIAF, but that it is also important that overlapping groups of malnourished children are not missed; focussing too narrowly, say on just those children who exhibit Wasting and Stunting, which recent analyses estimate a prevalence of around 3\% (Khara et al., 2017), may give the impression that serious malnutrition is not very prevalent. This would be a mistake, not least because the work of McDonald et al. (2013) showed clearly that when compared to children not experiencing any failures the odds of dying for children suffering from Stunting and Underweight are 3.4 greater and for children suffering from Wasting and Underweight they are 4.7 greater - not as high as Wasting and Stunting or the triple failure group at 12.3 - but a significant problem nonetheless and thus a problem well worth monitoring and acting upon, as mortality risks for Stunting and Underweight, and Wasting and Underweight are significantly higher than for Wasting, Stunting and Underweight on their own. 
The SDGs have moved the focus from underweight to stunting and wasting, on the grounds that children fail to reach an expected weight for their age because of wasting or stunting or both. The CIAF maintains the focus on stunting and wasting, as children who are underweight only constitute a small minority of children (1\% in this region). Variation in CIAF therefore will reflect primarily changes in wasting and stunting and by counting children who experience any of these two types of anthropometric failures the CIAF gives a more accurate picture of the full extent on malnutrition in a given region. In contrast the indicator of Multiple Malnutrition is to a much larger extent influenced by the percentage of people who are underweight, particularly underweight and stunted or underweight and wasted. Indeed considering only children who exhibit stunting and wasting (Khara et al., 2017) would lead to much smaller estimates. We have argued that there are good reasons for considering children who are also underweight and stunted or underweight and wasted.

This paper inevitably comes with limitations. Our estimated totals draw on the 2012 United Nations' World Population Prospects. Although most of our analysis focuses on the period before 2012, the revised 2017 World Population Prospects could be used to produce more accurate results of the total number of children affected for estimates after 2012. Our analysis also did not focus on gender differences in malnutrition and a much more in-depth analysis of gender differences for different types of combined anthropometric failures is needed. We also focused predominantly on the alarming and persistent inequalities across different levels of education, rurality, living standards and household conditions but individual characteristics of parents and children as well as variation in national and subnational economic output, infrastructure and healthcare provision should be further investigated.

With regards the situation in West and Central Africa, it is clear then than progress across the 2000s has been limited in terms of reducing both prevalence and the number of malnourished children, but also that the regional figures are dominated by one country - Nigeria. Data from the 2017 MICS report for Nigeria shows that Stunting and Wasting have remained high, at $44 \%$ and $11 \%$ respectively (National Bureau of Statistics (NBS) \& UNICEF 2018); this suggests the Central and West Africa region is already off track to meet SDG 2. Our analysis points to the importance of disaggregated analyses and data, to reflect the differing fortunes of rural and urban populations, and subgroups within such areas (e.g. the urban poor, the rural non-poor, etc). Sub-group analyses show that clear socioeconomic gradients and disparities persist, and in some instances widened (e.g. Cameroon) across the 2000 s.

In addition to food security, a child's living standards are key determinants of their nutritional status; in using the UN-HABITAT measure of slum-like conditions, it is clear that nutrition profiles of countries do not divide simply along urban and rural paths - i.e. the poor, be they urban or rural, and the conditions in which they live will determine the success or failure of any food security policies or nutrition interventions. Across all the measures of socio-economic status we used, the rural 'non-poor' did as well or better than their urban 'poor' counterparts. Understanding the disaggregated patterns of malnutrition, and which groups are exposed to which combinations of deficits or failures, will inform policy makers about the drivers behind persistent malnutrition. That said, tackling malnutrition effectively requires no new 
technologies, just the political will to address social and economic inequalities and injustice. In the absence of this, international targets like the SDGs will, like the MDGs, simply remain aspirations.

Compliance with Ethical Standards The authors of the study did not have to obtain ethical approval, as they only analysed secondary, fully anonymized individual-level data from the publicly available Demographic and Health Surveys and Multiple Indicator Cluster Surveys, as well as some country-level data.

Open Access This article is distributed under the terms of the Creative Commons Attribution 4.0 International License (http://creativecommons.org/licenses/by/4.0/), which permits unrestricted use, distribution, and reproduction in any medium, provided you give appropriate credit to the original author(s) and the source, provide a link to the Creative Commons license, and indicate if changes were made.

\section{References}

Aliaga, A., \& Ren, R. (2006). Optimal sample sizes for two-stage cluster sampling in demographic and health surveys. DHS Working Paper Series.

Bergeron, G., \& Castleman, T. (2012). Program responses to acute and chronic malnutrition: Divergences and convergences. Advances in Nutrition, 3(2), 242-249. https://doi.org/10.3945/an.111.001263.

Boerma, J. T. (1996). Child survival in developing countries: Can demographic and health surveys help to understand the determinants? Koninklijk Instituut voor de Tropen.

Booysen, F., van der Berg, S., Burger, R., von Maltitz, M., \& du Rand, G. (2008). Using an asset index to assess trends in poverty in seven sub-Saharan African countries. World Development, 36(6), 1113-1130. https://doi.org/10.1016/j.worlddev.2007.10.008.

Briend, A., Khara, T., \& Dolan, C. (2015). Wasting and stunting — Similarities and differences: Policy and programmatic implications. Food and Nutrition Bulletin, 36(1_suppl1), S15-S23. https://doi.org/10.1177 $/ 15648265150361 \mathrm{~s} 103$.

Cesare, M. D., Bhatti, Z., Soofi, S. B., Fortunato, L., Ezzati, M., \& Bhutta, Z. A. (2015). Geographical and socioeconomic inequalities in women and children's nutritional status in Pakistan in 2011: An analysis of data from a nationally representative survey. The Lancet Global Health, 3(4), e229-e239. https://doi. org/10.1016/s2214-109x(15)70001-x.

Checkley, W., Gilman, R. H., Epstein, L. D., Suarez, M., Diaz, J. F., Cabrera, L., Black, R. E., \& Sterling, C. R. (1997). Asymptomatic and symptomatic cryptosporidiosis: Their acute effect on weight gain in Peruvian children. American Journal of Epidemiology, 145(2), 156-163. https://doi.org/10.1093 /oxfordjournals.aje.a009086.

Checkley, W., Gilman, R. H., Black, R. E., Epstein, L. D., Cabrera, L., Sterling, C. R., \& Moulton, L. H. (2004). Effect of water and sanitation on childhood health in a poor Peruvian peri-urban community. The Lancet, 363(9403), 112-118. https://doi.org/10.1016/s0140-6736(03)15261-0.

Corsi, D. J., Neuman, M., Finlay, J. E., \& Subramanian, S. (2012). Demographic and health surveys: A profile. International Journal of Epidemiology, 41(6), 1602-1613. https://doi.org/10.1093/ije/dys184.

Dillingham, R., \& Guerrant, R. L. (2004). Childhood stunting: Measuring and stemming the staggering costs of inadequate water and sanitation. The Lancet, 363(9403), 94-95. https://doi.org/10.1016/s0140-6736(03 )15307-x.

Galobardes, B., Lynch, J., \& Smith, G. D. (2007). Measuring socioeconomic position in health research. British Medical Bulletin, 81-82(1), 21-37. https://doi.org/10.1093/bmb/ldm001.

Gerland, P. (1996). Socio-economic data and GIS: Datasets, databases, indicators and data integration issues. Arendal, Norway: United Nations Statistics Division.

Gordon, D. (2002). The international measurement of poverty and anti-poverty policies. In T. Peter \& G. David (series Ed.), World poverty: New policies to defeat an old enemy. Bristol: The policy press.

Hancioglu, A., \& Arnold, F. (2013). Measuring coverage in MNCH: Tracking Progress in health for women and children using DHS and MICS household surveys. PLoS Medicine, 10(5). https://doi.org/10.1371 /journal.pmed.1001391.

Heger Boyle, E., King, M., \& Sobek, M. (2018). IPUMS-demographic and health surveys. 
Howe, L. D., Hargreaves, J. R., \& Huttly, S. R. (2008). Issues in the construction of wealth indices for the measurement of socio-economic position in low-income countries. Emerging Themes in Epidemiology, 5(1). https://doi.org/10.1186/1742-7622-5-3.

Khara, T, \& Dolan, C. (2014). Technical briefing paper: The relationship between wasting and stunting, policy, programming and research implications. Emergency Nutrition Network.

Khara, T., Mwangome, M., Ngari, M., \& Dolan, C. (2017). Children concurrently wasted and stunted: A metaanalysis of prevalence data of children 6-59 months from 84 countries. Maternal \& Child Nutrition, 14(2). https://doi.org/10.1111/mcn.12516.

McDonald, C. M., Olofin, I., Flaxman, S., Fawzi, W. W., Spiegelman, D., Caulfield, L. E., et al. (2013). The effect of multiple anthropometric deficits on child mortality: Meta-analysis of individual data in 10 prospective studies from developing countries. The American Journal of Clinical Nutrition, 97(4), 896901. https://doi.org/10.3945/ajcn.112.047639.

Myatt, M., Khara, T., Schoenbuchner, S., Pietzsch, S., Dolan, C., Lelijveld, N., \& Briend, A. (2018). Children who are both wasted and stunted are also underweight and have a high risk of death: A descriptive epidemiology of multiple anthropometric deficits using data from 51 countries. Archives of Public Health, 76(1). https://doi.org/10.1186/s13690-018-0277-1.

Nabwera, H. M., Fulford, A. J., Moore, S. E., \& Prentice, A. M. (2017). Growth faltering in rural Gambian children after four decades of interventions: A retrospective cohort study. The Lancet Global Health, 5(2), e208-e216. https://doi.org/10.1016/s2214-109x(16)30355-2.

Nandy, S., \& Miranda, J. (2008). Overlooking undernutrition? Using a composite index of anthropometric failure to assess how underweight misses and misleads the assessment of undernutrition in young children. Social Science \& Medicine, 66(9), 1963-1966. https://doi.org/10.1016/j. socscimed.2008.01.021.

Nandy, S., \& Svedberg, P. (2012). The composite index of anthropometric failure (CIAF): An alternative Indicator for malnutrition in young children. Handbook of Anthropometry, 127-137. https://doi. org/10.1007/978-1-4419-1788-1_6.

Nandy, S., Irving, M., Gordon, D., Subramanian, S., \& Smith, G. D. (2005). Poverty, child undernutrition and morbidity: New evidence from India. Bulletin of the World Health Organization, 83, 210-216.

National Bureau of Statistics (NBS), \& UNICEF. (2018). 2017 multiple Indicator cluster survey 2016-17, survey findings report. Abuja: National Bureau of Statistics and United Nations Children's Fund.

Olofin, I., McDonald, C. M., Ezzati, M., Flaxman, S., Black, R. E., Fawzi, W. W., et al. (2013). Associations of suboptimal growth with all-cause and cause-specific mortality in children under five years: A pooled analysis of ten prospective studies. PLoS One, 8(5), e64636. https://doi.org/10.1371/journal. pone.0064636.

Pelletier, D. L., Frongillo, E. A., Jr., Schroeder, D. G., \& Habicht, J.-P. (1995). The effects of malnutrition on child mortality in developing countries. Bulletin of the World Health Organization, 73(4), 443-448.

Pemberton, S., Gordon, D., Nandy, S., Pantazis, C., \& Townsend, P. (2005). The relationship between child poverty and child rights: The role of indicators. In A. Minujin, E. Delamonica, \& M. Komarecki (Eds.), Human rights and social policies for children and women: The multiple Indicator cluster survey (MICS) in practice (pp. 47-61). New York: New School University.

Pullum, T. W., Schoumaker, B., Becker, S., \& Bradley, S. E. (2013). An assessment of DHS estimates of fertility and under-five mortality. 28.

Rutstein, S. O., \& Johnson, K. (2004). The DHS wealth index. Calverton, Maryland: ORC Macro.

Rutstein, S. O., \& Rojas, G. (2003). Guide to DHS statistics. Calverton, MD: ORC Macro.

Schroeder, D., \& Brown, K. H. (1994). Nutritional status as a predictor of child survival: Summarizing the association and quantifying its global impact. Bulletin of the World Health Organization, 72(4), 569.

Smith, L. C., Ruel, M. T., \& Ndiaye, A. (2005). Why is child malnutrition lower in urban than in rural areas? Evidence from 36 developing countries. World Development, 33(8), 1285-1305. https://doi.org/10.1016/j. worlddev.2005.03.002.

Svedberg, P. (2000). Poverty and undernutrition: Theory, measurement, and policy. Clarendon Press.

Tomkins, A. (2000). Malnutrition, morbidity and mortality in children and their mothers. Proceedings of the Nutrition Society, 59(01), 135-146. https://doi.org/10.1017/s0029665100000161.

Tomkins, A., \& Watson, F. (1989). Malnutrition and infection: A review. Geneva: World Health Organisation/ ACC/SCN.

UNDESA. (2016). SDGs Overview.

UNDESA. (2017). SDGs Report Overview.

UN-HABITAT. (2003). The Challenge of Slums - Global Report on Human Settlements. London: nited Nations Human Settlements Programme (UN-Habitat). 
UN-HABITAT. (2016). World cities report 2016 - urbanisation and development - emerging futures. Nairobi: UN-HABITAT.

UNICEF. (2015). UNICEF's approach to scaling up nurtirtion for Morthers and their children. New York: UNICEF.

UNICEF, WHO, \& World Bank. (2015). Levels and trends in child malnutrition: UNICEF-WHO-the World Bank joint child malnutrition estimates. New York: UNICEF.

United Nations. (2015). The millennium development goals report 2015. New York City: United Nations.

Vaessen, M. (1996). The potential of the demographic and health surveys (DHS) for the evaluation and monitoring of maternal and child health indicators. Paris: CICRED/UNFPA.

Vella, V., Tomkins, A., Ndiku, J., Marshal, T., \& Cortinovis, I. (1994). Anthropometry as a predictor for mortality among Ugandan children, allowing for socio-economic variables. European Journal of Clinical Nutrition, 48(3), 189-197.

Vollmer, S., Harttgen, K., Kupka, R., \& Subramanian, S. V. (2017). Levels and trends of childhood undernutrition by wealth and education according to a composite index of anthropometric failure: Evidence from 146 demographic and health surveys from 39 countries. BMJ Global Health, 2(2). https://doi.org/10.1136/bmjgh-2016-000206.

WHO. (1995). Expert committee on nutrition and physical status: Uses and interpretation of anthropometry. Geneva: World Health Organisation.

Publisher's Note Springer Nature remains neutral with regard to jurisdictional claims in published maps and institutional affiliations. 